Article

\title{
Laboratory and Field Experiments on the Effect of Vinyl Acetate Polymer-Reinforced Soil
}

\author{
Zezhuo Song ${ }^{1} \oplus$, Jin Liu ${ }^{1}, * \oplus$, Yuxia Bai ${ }^{1}$, Jihong Wei ${ }^{1}$, Ding Li $^{1}$, Qiongya Wang ${ }^{1}$, \\ Zhihao Chen ${ }^{1}$, Debi Prasanna Kanungo ${ }^{2}$ and Wei Qian ${ }^{1}$ \\ 1 School of Earth Sciences and Engineering, Hohai University, Nanjing 210098, China; szzhhu@163.com (Z.S.); \\ byxhhu@163.com (Y.B.); weijhhhu@163.com (J.W.); geodamon617@vip.163.com (D.L.); \\ hhu_wqy@163.com (Q.W.); hhuczh@163.com (Z.C.); wei.geoserve@gmail.com (W.Q.) \\ 2 CSIR-Central Building Research Institute (CBRI), Roorkee 247667, India; debi.kanungo@gmail.com \\ * Correspondence: jinliu920@163.com or mydream@hhu.edu.cn; Tel.: +86-139-1397-6590
}

Received: 23 November 2018; Accepted: 3 January 2019; Published: 8 January 2019

\begin{abstract}
Soil stabilizer can enhance the soil properties, which can improve ecological environmental problems such as soil erosion and slope instability. This study investigates the water-related and mechanical properties of soil stabilization using a polymer soil stabilizer solution synthesized from vinyl acetate polymer. The water properties test, mechanical properties test, durability test and seed growth test were carried out in the laboratory. Also, the effect of vinyl acetate polymer was verified by field tests. The results revealed that vinyl acetate polymer can enhance the water-retaining property, anti-erosion resistance, strength property and durability of soil, all of which increase with the increase of polymer concentration. At the same time, the polymer also has a certain promoting effect on vegetation growth. In addition, field tests proved that vinyl acetate polymer has good effects on soil engineering. These results could be applied as a reference for vinyl acetate polymer-improved soil engineering.
\end{abstract}

Keywords: vinyl acetate polymer; soil improvement; topsoil; water property; mechanical property; durability; field test

\section{Introduction}

With the development of the social economy, human engineering activities are having a greater and greater impact on the ecological environment, which leads to a series of ecological environmental problems, such as water and soil loss, landslides, dust emission, and so on [1-3]. According to some investigations, the average loss of soil in the United States is $8.7 \times 106 \mathrm{~kg} / \mathrm{km}^{2}$ every year [4]. Due to large-scale engineering construction, many bare soil slopes have been formed. These slopes are prone to slope erosion, soil erosion, and other disasters. Therefore, adopting various physical and chemical methods to prevent soil erosion and other geological and environmental problems has always been a hot research topic globally.

Soil stabilizer, as a new environmentally friendly soil improvement material, was advanced in developed countries such as the United States and Japan in 1970s. According to the main components, soil stabilizers can be divided into five major categories: lime cement soil stabilizer [5-8], slag silicate soil stabilizer [9-12], ionic soil stabilizer [13-16], bio-enzyme soil stabilizer [17,18] and polymer soil stabilizer [19-23]. Polymer soil stabilizer has become a hot spot of research in soil stabilization materials, because of advantages that include less incorporation, stable curing effect and ecological environmental protection. Naeini et al. [24] used self-developed hydrophilic polymers to strengthen the soil. The polymer can significantly increase the compressive strength of soil. Zezin et al. [25] developed an electrolyte polymer that can effectively solve the problem of radioactive soil particle 
diffusion. Collins et al. [26] found that a high molecular polymer can reduce the thickness of the hydrated film around the soil particles, which makes the connection of soil particles more compact.

In the present study, polymer soil stabilizer solution is synthesized from vinyl acetate polymer as a chemical treatment material of soil. The water properties test, including water-retaining property test and rainfall erosion test, mechanical properties test, including unconfined compression test and direct shear test, durability test and seed growth test were carried out in the laboratory. Also, the effect of vinyl acetate polymer was verified by field tests. These results could be applied as a reference for vinyl acetate polymer-improved soil engineering, especially for the surface protection of slopes.

\section{Materials and Methods}

\subsection{Vinyl Acetate Polymer}

Vinyl acetate polymer, which was synthesized in the laboratory, is a white emulsion (Figure 1). The active ingredient of vinyl acetate polymer is latex particles, which contain a large number of polymer chains. There is a mass of hydrophilic carboxyl groups $(-\mathrm{COOH})$ and hydroxyl groups $(-\mathrm{OH})$ in the polymer chain. The basic physical and chemical properties of vinyl acetate polymer were measured in the laboratory. The measured results are shown in Table 1.

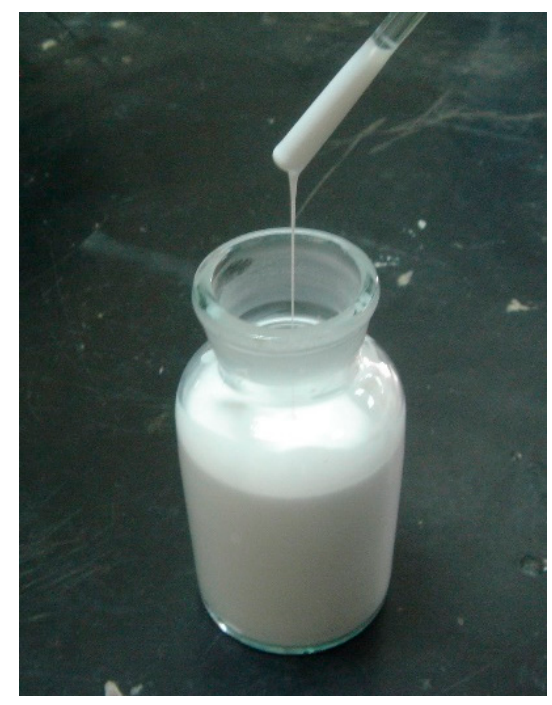

Figure 1. Vinyl acetate polymer.

Table 1. The basic physical and chemical properties of vinyl acetate polymer.

\begin{tabular}{cccccc}
\hline pH & $\begin{array}{c}\text { Viscosity } \\
(\mathbf{M P a} \cdot \mathbf{s})\end{array}$ & $\begin{array}{c}\text { Relative } \\
\text { Density (Gs) }\end{array}$ & Solid Content (\%) & $\begin{array}{c}\text { Water } \\
\text { Absorption (\%) }\end{array}$ & Gel Rate (\%) \\
\hline $6-7$ & $400-3000$ & $1.05-1.07$ & $41-45$ & $34-38$ & $1.48-1.53$ \\
\hline
\end{tabular}

The basic synthetic material of vinyl acetate polymer is vinyl acetate. Other functional modifier monomer and auxiliary materials are also added in the synthesis formulation. According to the functional requirements of the polymer, several protective colloids, emulsifiers, buffers, stabilizers, plasticizers and anti-ultraviolet materials are added to improve the function of the polymer.

The polymerization process is described as follows. The water was first mixed with the polyvinyl alcohol. Persulfate and vinyl acetate were added to the mixture. After that, the mixture was loaded into a reaction still for $20 \mathrm{~min}$ to do the polymerization. Then the proportion of vinyl acetate, methyl methacrylate and acrylate were mixed. The mixture was dripped into the existing reaction system over $2-3 \mathrm{~h}$. After finishing the dripping, the reactants were reacted at $60-73{ }^{\circ} \mathrm{C}$ for $30-60 \mathrm{~min}$. Subsequently, the reaction temperature was reduced to $50-55^{\circ} \mathrm{C}$ and the emulsifiers, buffers, stabilizers, plasticizers 
and so on were added into the reaction system. Finally, the mixture was fully stirred and cooled to room temperature to obtain vinyl acetate polymer.

\subsection{Modified Mechanism of Vinyl Acetate Polymer}

Vinyl acetate polymer is a kind of polymer emulsion with strong water resistance. It exhibits negative electricity due to the adsorption of a large amount of anions. When the polymer is in contact with soil particles, it is adsorbed onto the surface of the soil due to electrostatic attraction (Figure 2a). With the diffusion and volatilization of water, the polymer chains are extended.

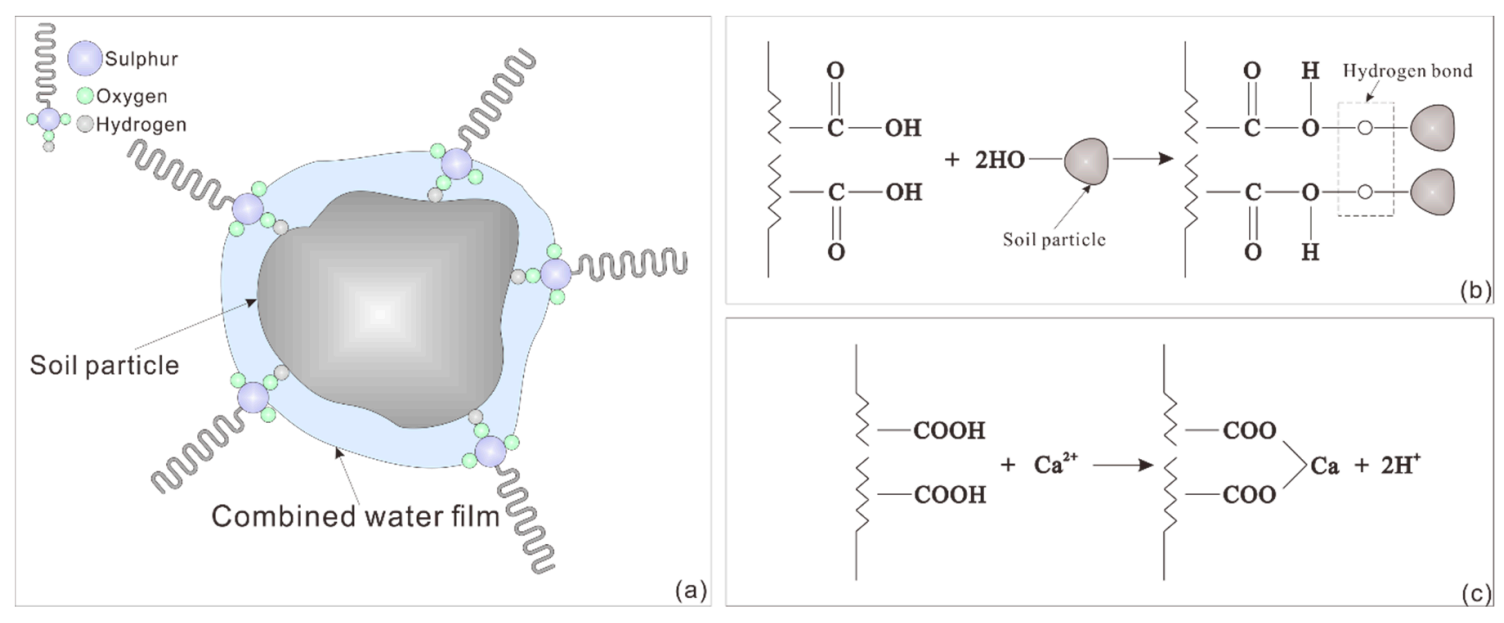

Figure 2. The interaction between polymer and soil particle: (a) Schematic diagram; (b) formation of hydrogen bonds; (c) cation substitution reaction.

The carboxyl groups on the polymer chains form hydrogen bonds with hydroxyl groups on the surface of the soil particles (Figure $2 b$ ). With the increase of polymer concentration, the number of hydrogen bonds becomes greater and greater. Due to the existence of a large number of hydrogen bonds, the structure of the soil becomes more stable. The hydrogen ions in the hydrophilic group of polymer chains replace the alkali metal ions on the surface of the soil particles (Figure 2c). This can reduce the thickness of the electric double layer of clay particles, by which the increasing attraction energy between soil particles promotes soil aggregation. Due to the presence of hydrophobic long chains in the molecule, a reticular membrane structure is formed on the particle surface and in the gaps of soil particles via diffusion, infiltration and winding, leading to the bonding forces between soil particles being further enhanced. The whole volume of soil becomes a solid space net structure system with stabilized characteristics.

The improved soil was subjected to scanning electron microscopy to obtain the microscopic state. Figure 3 is the SEM micrographs of improved soil in different magnifications. From Figure $3 a, b$ it can be seen that a part of the polymer permeates the interior of the soil and fills the pores between most of the particles, which enhances the connecting force between the particles, after the polymer is in contact with soil. The reticulated membrane formed on the surface of soil particles by vinyl acetate polymer is shown in Figure 3c. It can be found that the connection between reticulated membrane and soil particles is very close. The reticulated membrane has good hydrophobicity, toughness and strength.

\subsection{Soil Characterization}

The soil used in the laboratory experiments was obtained from Nanjing, Jiangsu Province, China, which is also the location of field test in Section 4. The soil was dried at $105{ }^{\circ} \mathrm{C}$, crushed and sieved to $2 \mathrm{~mm}$ to remove the gravels. The Atterberg liquid limit of the soil was found to be 52.6, and the plasticity index was 17.3. The maximum dry density $\left(\rho_{\max }\right)$ and the optimum water content of the soil were determined as $1.73 \mathrm{~g} / \mathrm{cm}^{3}$ and $15.4 \%$, respectively, which were determined by the standard 
Proctor test. It belongs to the clay based on the ASTM standard (ASTM D2487-00). The content of $0.015-1 \mathrm{~mm}$ soil particles is $73 \%$. The soil is free of organic matter and pollutants. In addition, the main mineral composition of soil is quartz, mica, feldspar, illite and calcite, which account for more than $96 \%$ of the mineral composition.

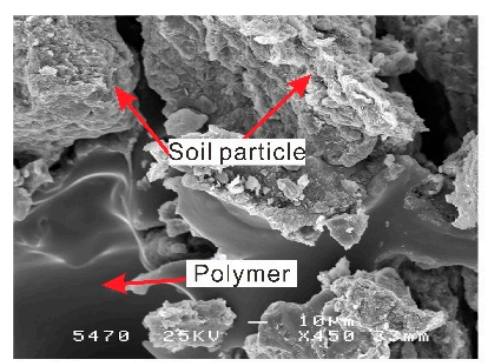

(a)

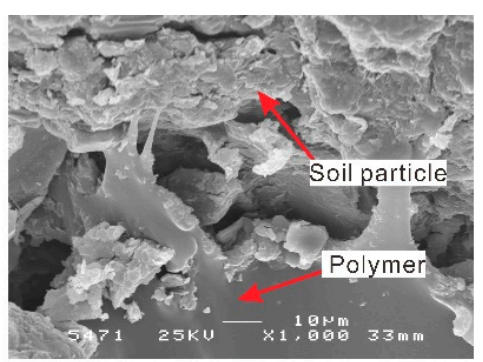

(b)

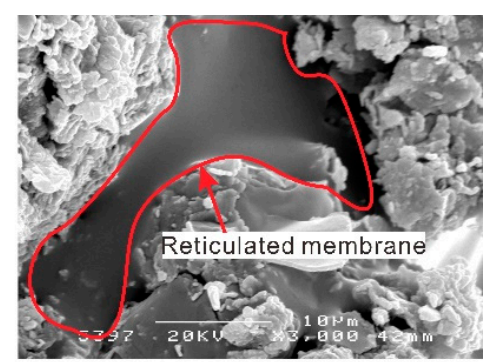

(c)

Figure 3. SEM image of section of inner soil modified with polymer: (a) $\times 450$; (b) $\times 1000$; (c) $\times 3000$.

\subsection{Water Property Test}

\subsubsection{Water-Retaining Property Test}

Water-retaining property is one aspect of soil improvement by soil stabilizer. It refers to the relative stability of water in the soil. It prevents the soil from hardening and allows the vegetation to absorb sufficient moisture and nutrients. The purpose of this test is to understand the effect of vinyl acetate polymer on soil water-retaining property.

In this experiment, $500 \mathrm{~g}$ of soil was put into an evaporating box with $20 \mathrm{~cm}$ length, $10 \mathrm{~cm}$ width and $5 \mathrm{~cm}$ height. The box was shaken so that the soil was evenly distributed. Then, five locations were selected to measure the height of the soil. When the difference between the five heights is less than $0.1 \mathrm{~cm}$, the soil can be considered uniform. Otherwise, the soil is removed and reloaded. The soil can be considered evenly distributed. The density and the porosity were $1.73 \mathrm{~g} / \mathrm{cm}^{3}$ and $0.57 .300 \mathrm{~mL}$ of polymer diluents with the concentrations of $0 \%, 10 \%, 20 \%$ and $30 \%$ (S1, S2, S3 and S4) was sprayed on the surface of the soil. The average thickness of spray on topsoil was $3 \mathrm{~cm}$, which was controlled by the density of soil, the concentration of polymer diluent and the volume of spraying. Then the evaporation box was placed in a curing box with a temperature of around $40{ }^{\circ} \mathrm{C}$ for test. After $24 \mathrm{~h}$, the soil in the evaporation box was weighed until the difference in weight between the two was no greater than $1 \mathrm{~g}$. The evaporativity was given by:

$$
E_{e}=\frac{M_{1}-M_{2}}{M_{0}} \times 100 \%,
$$

where $E_{e}(\%)$ is defined as the evaporativity of soil; $M_{1}(\mathrm{~g})$ is the weight of soil at beginning; $M_{2}(\mathrm{~g})$ is the weight of soil after a period of time of evaporation; $M_{0}(\mathrm{~g})$ is the weight of the dried soil.

\subsubsection{Rainfall Erosion Test}

The purpose of rainfall erosion test is to test the anti-erosion resistance of soil improved by vinyl acetate polymer. This experiment is carried out using self-designed rainfall erosion test simulator. The schematic diagram of the test simulator is shown in Figure 4.

The size of the tray used in the experiment is $16 \mathrm{~cm} \times 16 \mathrm{~cm} \times 3 \mathrm{~cm}$. In the experiment, the tray is full of dried soil, the weight of which is $2000 \mathrm{~g}$. The tray was shaken so that the soil was evenly distributed. Then, five locations were selected to measure the height of the soil. When the difference between the five heights is less than $0.1 \mathrm{~cm}$, the soil can be considered uniform. Otherwise, the soil is removed and reloaded. The soil can be considered evenly distributed. The density and the porosity were $1.73 \mathrm{~g} / \mathrm{cm}^{3}$ and 0.57 . After finishing compaction, the weight of the whole tray was weighed. The polymer diluents with concentrations of $0 \%, 10 \%, 20 \%$ and $30 \%$ (S5, S6, S7 and S8) were evenly 
sprayed on the surface of the soil. The spray amount was $3 \mathrm{~L} / \mathrm{m}^{2}$. The average thickness of the spray on the topsoil was $3 \mathrm{~cm}$, which was controlled by the density of soil, the concentration of the polymer diluent, and the volume of spraying. The tray was placed on a slope with $30^{\circ}$ gradient, which is also the gradient of the slope in the field test, after curing at $20^{\circ} \mathrm{C}$ for $24 \mathrm{~h}$. The intensity of rainfall was $2.7 \mathrm{~L} / \mathrm{min}$, which is the maximum annual precipitation intensity in Nanjing. For unreinforced soil, soil failure occurred after $30 \mathrm{~min}$ erosion. Therefore, the rainfall time was $30 \mathrm{~min}$ in this test. In addition, a collecting bucket was used to collect sediment loss. The weight of the soil in the collecting bucket was weighted after being dried for $24 \mathrm{~h}$. The erosion rate was given by:

$$
E_{p}=\frac{\Delta m}{m_{1}-m_{0}} \times 100 \%,
$$

where $E_{p}(\%)$ is defined as the erosion rate of soil; $\Delta m(\mathrm{~g})$ is the weight of dried soil in the collecting bucket; $m_{1}(\mathrm{~g})$ is the weight of soil and the tray; $m_{0}(\mathrm{~g})$ is the weight of the tray.

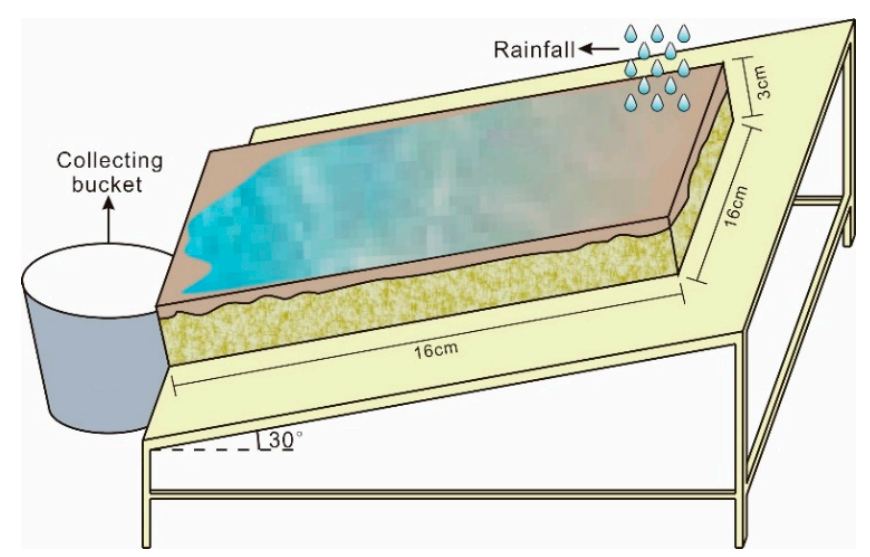

Figure 4. The rainfall erosion test simulator.

\subsection{Mechanical Property Test}

\subsubsection{Unconfined Compression Test}

To determine the unconfined compression strength of the improved soil, unconfined compression tests were performed. In the unconfined compression test, the soil was mixed with the vinyl acetate polymer dilution by an agitator. Four-layered compaction was adopted to test specimens with $39.1 \mathrm{~mm}$ diameter and $80 \mathrm{~mm}$ height. The specimen was statically compressed by a jack with a customized mold. The optimal values (for full mass stabilized soil) were used for all specimens, and were $15.4 \%$ in water content and $1.73 \mathrm{~g} / \mathrm{cm}^{3}$ in density. The concentrations of the polymer were $0 \%, 10 \%, 20 \%$ and $30 \%(\mathrm{~S} 9, \mathrm{~S} 10, \mathrm{~S} 11$ and S12) in the test. After the specimen preparation, the specimens were cured at $20{ }^{\circ} \mathrm{C}$ for $24 \mathrm{~h}$. In the test, the YYW-2 unconfined compressional strain control device (Nanjing Nantu Instrument Equipment Co. Ltd., Nanjing, China) was used, and the controlling strain rate was $2.4 \mathrm{~mm} / \mathrm{min}$ [27]. The test was based on the ASTM standard (ASTM D2166-00). For the specimens at each relevant parameter, the test was repeated three times.

\subsubsection{Direct Shear Test}

To determine the cohesion and internal friction angle of the improved soil, direct shear tests were performed. The direct shear strength of the 61.8-mm-diameter and 20-mm-height specimens was measured at $50 \mathrm{kPa}, 100 \mathrm{kPa}, 200 \mathrm{kPa}$ and $300 \mathrm{kPa}$ vertical stress, for which a ZJ type strain controlled direct shear apparatus (Nanjing Nantu Instrument Equipment Co. Ltd., Nanjing, China) was used. The specimen was statically compressed by a jack with a customized mold. The optimal values (for full mass stabilized soil) were used for all specimens, and were $15.4 \%$ in water content and $1.73 \mathrm{~g} / \mathrm{cm}^{3}$ in 
density. The concentrations of the polymer were $0 \%, 10 \%, 20 \%$ and $30 \%(\mathrm{~S} 13, \mathrm{~S} 14, \mathrm{~S} 15$ and S16) in the test. After the specimen preparation, the specimens were cured at indoor temperature for $24 \mathrm{~h}$. In the test, the direct shear rate was $0.8 \mathrm{~mm} / \mathrm{min}$ [28]. The test was based on the ASTM standard (ASTM D3080-98). The cohesion and internal friction angle were calculated by the experimental data based on Coulomb's law. Four normal pressures, which include $50 \mathrm{kPa}, 100 \mathrm{kPa}, 200 \mathrm{kPa}$ and $300 \mathrm{kPa}$ in present study, and four corresponding peak shear stresses were used to fit a straight line. The intercept and slope of the straight line are cohesion and the tangent value of the internal friction angle. For the specimens at each relevant parameter, the test was repeated three times.

\subsection{Durability Test}

The durability of the soil mainly includes frost resistance, drying and wetting resistance, ultraviolet radiation resistance, and so on. This experiment mainly studies the effect of vinyl acetate polymer on frost resistance and light resistance of soil. The durability of soil is a major property related to climate conditions.

In the durability test, the dried soil was mixed with the vinyl acetate polymer dilution. The unconfined compression strength increased with the increasing polymer concentration. When the polymer concentration was more than $20 \%$, the unconfined compression strength tended to be stable. Therefore, the concentration of the polymer was $20 \%$. The optimal values (for full mass stabilized soil) were used for all specimens in this test, and were $15.4 \%$ in water content and $1.73 \mathrm{~g} / \mathrm{cm}^{3}$ in density. After the preparation, the specimens were kept in a curing box with a temperature of around $20{ }^{\circ} \mathrm{C}$ for $24 \mathrm{~h}$.

To test the frost resistance of the improved soil, the specimens were first kept in a $-20{ }^{\circ} \mathrm{C}$ environment for $12 \mathrm{~h}$. In addition, they were then placed in a drying box with a temperature of around $20{ }^{\circ} \mathrm{C}$ for $12 \mathrm{~h}$. This is a freeze-thaw cycle. The indoor temperature is $20^{\circ} \mathrm{C}$. The annual temperature range of Nanjing is $40^{\circ} \mathrm{C}$, so the temperature cycle of $-/+20^{\circ} \mathrm{C}$ was chosen. In the test, the number of freeze-thaw cycles was set at 0, 2, 4, 6, 8 and 10 (S17, S18, S19, S20, S21 and S22). After the freeze-thaw cycles, the unconfined compression test was carried out with a YYW-2 unconfined compressional strain control device to evaluate the durability of improved soil with different cycles. The loading rate of the unconfined compression test is $2.4 \mathrm{~mm} / \mathrm{min}$. The unconfined compression test was based on the ASTM standard (ASTM D2166-00). For the specimens at each relevant parameter, the test was repeated three times.

To test the light resistance of improved soil, the specimens were kept in an artificial climate box with a temperature of around $40^{\circ} \mathrm{C}$ because the annual maximum temperature in Nanjing is about $40^{\circ} \mathrm{C}$, and 22,000 Lx intensity of light. In the experiment, the illumination time was set at $0 \mathrm{~h}, 120 \mathrm{~h}$, $240 \mathrm{~h}, 480 \mathrm{~h}, 600 \mathrm{~h}$ and $720 \mathrm{~h}$ (S23, S24, S25, S26, S27 and S28), respectively. After that, the specimens were also tested for the unconfined compression strength to evaluate the durability of improved soil with different illumination time. For the specimens at each relevant parameter, the test was repeated three times.

\subsection{Seed Growth Test}

Many existing soil stabilizers have adverse effects on plant growth. To understand the effect of vinyl acetate polymer on plant growth, a seed growth test was carried out.

Bahiagrass was selected as the experimental vegetation in this test. Equal numbers of seeds were sown into a petri dish, which was filled with $200 \mathrm{~g}$ of soil in advance. Subsequently, $3 \mathrm{~L} / \mathrm{m}^{2}$ of polymer solution with polymer concentrations of $0 \%, 10 \%, 20 \%$ and 30\% (S29, S30, S31 and S32) was sprayed on soil surfaces. The petri dishes were kept in an artificial climate box with a temperature of around $28^{\circ} \mathrm{C}$, because the average temperature of Nanjing in September is $28^{\circ} \mathrm{C}$. The soil was watered regularly, and the germination and growth of vegetation could be observed. The quantity of water sprayed on the specimen is $100 \mathrm{~g}$. 


\section{Results and Analysis}

\subsection{Water Property Test}

\subsubsection{Water-Retaining Property Test}

Figure 5 shows the data results of water-retaining property test. It can be seen from Figure 5 that as the concentration of polymer increases, the evaporation of soil decreases within $80 \mathrm{~h}$. This implies that the water-retaining property of soil increases with the concentration of polymer. To be specific, the water-retaining property of soil with polymer concentration of $10 \%$ is similar to that of water until $48 \mathrm{~h}$. After $48 \mathrm{~h}$, there are differences between the two. When the concentration of polymer is high, the water-retaining property of soil can be significantly improved. Spraying $30 \%$ polymer solution can reduce soil evaporation by $13.16 \%$ compared with water.

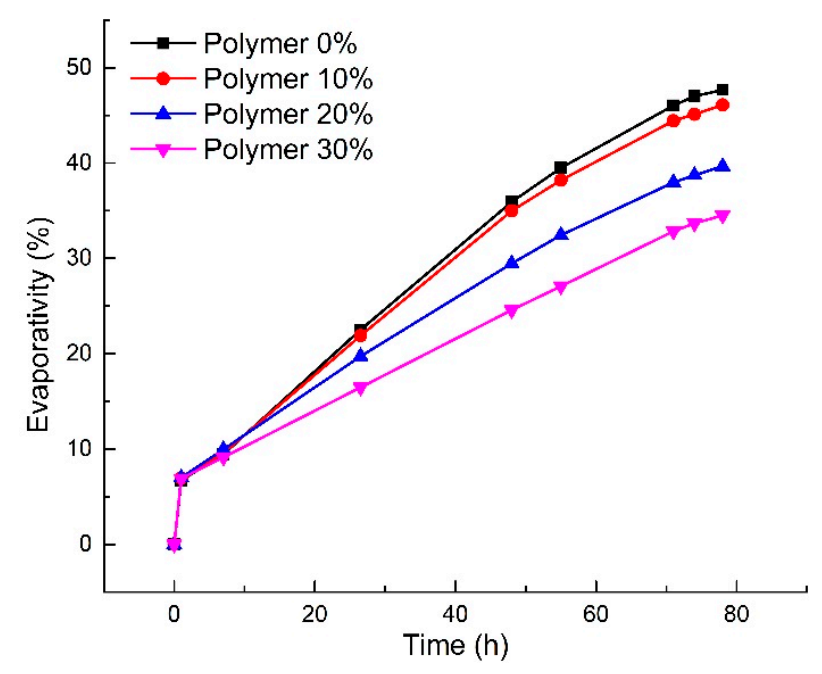

Figure 5. The water retaining vs. time on samples S1-S4.

Hydrophilic groups in vinyl acetate polymer form a close bond with soil particles through hydrogen bonds and cation exchange. The long hydrophobic C-C chain on the main chain forms a layer of elastic and ductile reticular membrane on the surface of soil particles through diffusion, infiltration and winding. The reticular membrane structure has good water absorption and can absorb more water. Compared with the quality of the specimen, the quality of the membrane can be neglected. In addition, the presence of reticular membrane structure provides more storage space for water (Figure 6). Due to the increase of water content in soil, the specific heat capacity of soil increased. When soil is heated, evaporation occurs and water content decreases slowly [29,30].

\subsubsection{Rainfall Erosion Test}

The data results of the rainfall erosion test are shown in Table 2. As shown in Table 2, the addition of polymer can obviously enhance the soil erosion resistance. When the polymer concentration is $0 \%$, the soil erosion rate is $70.2 \%$. The erosion and failure phenomena of the soil surface are obvious, and a large number of gullies are developed. The erosion rate of soil decreases with the increase in polymer concentration. The soil structure is basically intact, and the surface gully is not obvious. When the polymer concentration reaches $20 \%$ and $30 \%$, the erosion rates of soil are only $5.5 \%$ and $1.1 \%$ respectively. 

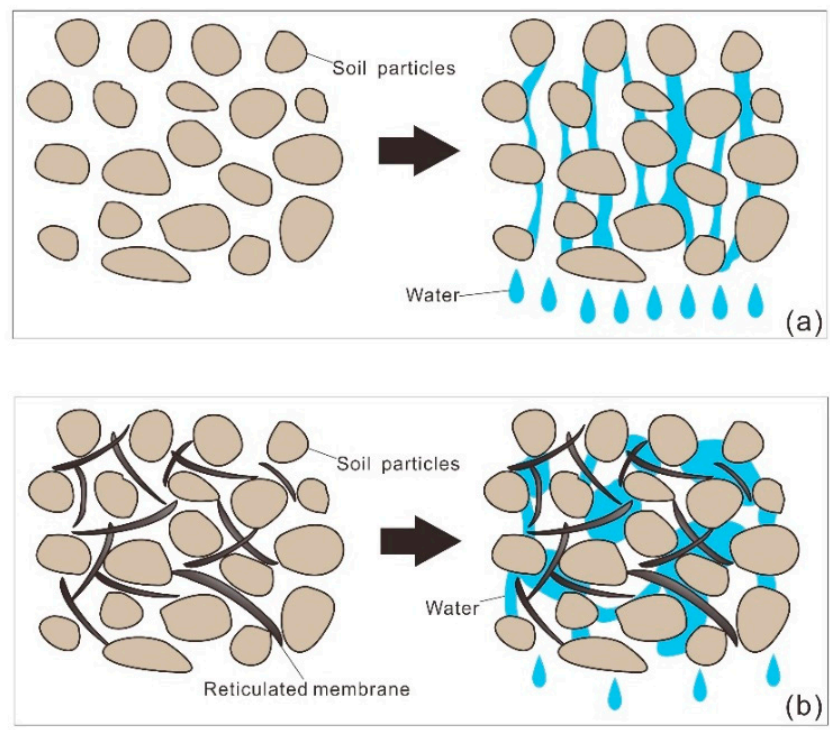

Figure 6. The schematic diagram of water-retaining property: (a) Soil; (b) soil improved by polymer.

Table 2. The rainfall erosion test results.

\begin{tabular}{cccc}
\hline Specimens Reference & Polymer Concentration $(\mathbf{\%})$ & $\boldsymbol{\Delta} \boldsymbol{m}(\mathbf{g})$ & $\boldsymbol{E}_{\boldsymbol{p}} \mathbf{( \% )}$ \\
\hline S5 & 0 & 1404.2 & 70.2 \\
S6 & 10 & 260.3 & 13.0 \\
S7 & 20 & 110.8 & 5.5 \\
S8 & 30 & 22.5 & 1.1 \\
\hline
\end{tabular}

When the stabilizer is sprayed on the soil, the hydrophilic groups in the stabilizer are connected to the soil particles by hydrogen bonding and cation exchange. Hydrophobic $\mathrm{C}-\mathrm{C}$ long chains form reticular membrane structures in soil through diffusion, winding and inclusion. Therefore, the integrity of the soil has been greatly improved. With the continuous improvement of soil integrity, the erosion resistance of soil surface is gradually enhanced.

\subsection{Mechanical Property Test}

\subsubsection{Unconfined Compression Test}

Table 3 shows the effect of concentration on the unconfined compression strength of soil. It can be seen from Table 3 that the trend of the unconfined compression strength increases with the increase in polymer concentration. The unconfined compression strength of soil increases from $76.3 \mathrm{kPa}$ to $205.4 \mathrm{kPa}$ with the polymer concentration increase from $0 \%$ to $30 \%$, which indicates that the water-based organic polymer contributed to a significant improvement in soil on the unconfined compression strength.

Table 3. Effect of polymer concentration on unconfined compression strength of soil.

\begin{tabular}{ccc}
\hline Specimens Reference & Polymer Concentration (\%) & $\begin{array}{c}\text { Unconfined Compression } \\
\text { Strength/Standard Deviations (kPa) }\end{array}$ \\
\hline S9 & 0 & $76.3 / 0.58$ \\
S10 & 10 & $189.3 / 1.34$ \\
S11 & 20 & $198.2 / 3.88$ \\
S12 & 30 & $205.4 / 8.8$ \\
\hline
\end{tabular}

After $24 \mathrm{~h}$ of curing, a series of physical and chemical reactions took place between the polymer and the soil particles. Through phase diffusion, permeation and winding, the polymer forms reticular 
membrane structure between soil particles, which enhances the bonding force between the soil particles and enhances the strength of samples. With the increase of the polymer concentration, the interaction between the polymer and the soil particles is also strengthened; so, the strength of the sample increases with the increase in polymer concentration.

\subsubsection{Direct Shear Test}

The data results of the direct shear test are shown in Table 4. As observed, the cohesion of soil increases with the increase in polymer concentration. The cohesion of soil increases rapidly with the polymer concentration between $0 \%$ and $10 \%$. Between $10 \%$ and $30 \%$ concentration, the cohesion of soil rises very slowly. Table 4 also shows that the internal friction angles of soil with polymer and without polymer are almost similar (about $29^{\circ}-30^{\circ}$ ). This implies that the addition of polymer to the soil does not influence the internal friction angle. The increase in shear strength of the soil is attributed to the improvement in inter-particle cohesion.

Table 4. Cohesions and internal friction angles of polymer improved soil.

\begin{tabular}{cccc}
\hline Specimens Reference & Polymer Concentration (\%) & $\begin{array}{c}\text { Cohesion/Standard } \\
\text { Deviations (kPa) }\end{array}$ & $\begin{array}{c}\text { Internal Friction } \\
\text { Angle/Standard Deviations }\left({ }^{\circ}\right)\end{array}$ \\
\hline S13 & 0 & $56.0 / 1.36$ & $29.5 / 1.03$ \\
S14 & 10 & $365.23 / 5.58$ & $29.1 / 1.16$ \\
S15 & 20 & $373.17 / 18.63$ & $30.0 / 0.96$ \\
S16 & 30 & $384.9 / 18.59$ & $30.1 / 1.20$ \\
\hline
\end{tabular}

Because of the increase in the connection force between soil particles and the reticulated membrane structure created by the polymer, the cohesion of soil increased. In contrast, the cohesion and internal friction angle of the soil without polymer and curing were $56 \mathrm{kPa}$ and $29.5^{\circ}$, respectively. After $24 \mathrm{~h}$ of curing, the water content of the sample decreased. The thickness of hydration film and the distance between soil particles were all reduced. With the increase of contact area, the surface tension of capillary water between soil particles increased significantly. These changes lead to a sharp increase in cohesion and internal friction angle of soil. The connection force between soil particles increases with the increase in the polymer concentration, which causes the cohesion of soil to gradually increase with the increase in the polymer concentration. The internal friction angle of soil is mainly related to the strength of soil particles. Because the polymer did not affect the strength of soil particles, the internal friction angle of the soil changed very little.

\subsection{Durability Test}

Figure 7a illustrates the relationship between the number of freeze-thaw cycles and the unconfined compression strength of the improved soil. It can be clearly observed that as the number of freeze-thaw cycles increases, the unconfined compressive strength of soil gradually decreases. After four freeze-thaw cycles, the trend of strength decline slowed down.

Figure $7 \mathrm{~b}$ illustrates the relationship between illumination time and unconfined compression strength of the improved soil. As shown in Figure 7b, the unconfined compressive strength of soil initially increases with the increase in illumination time. The unconfined compressive strength reaches maximum (i.e., $5.05 \mathrm{MPa}$ ) at about $360 \mathrm{~h}$. As the illumination time continues to increase, the strength of the soil decreases gradually at a slower rate.

The reticular membrane structure formed by vinyl acetate polymer was able to improve the anti-aging property and anti-freezing property of soil. The membrane structure itself has certain characteristics of water loss and water absorption. After water loss, the membrane structure is hardened, and the strength is increased. Whereas, after water absorption, it is softened to a certain extent, and the strength is decreased. In the freeze-thaw cycle, the hydrated film on the surface of the soil particles causes the phenomenon of frost expansion, which weakens the reticular membrane structure and the strength of the soil. After several cycles of frost heave, the reticular membrane 
structure reaches a stable state again, so the trend of strength decline shows down. Under strong light irradiation, the reticular membrane structure itself produces a certain amount of water loss, and the strength is enhanced. Meanwhile, the soil particles also lose water. Therefore, the strength of the improved soil tends to increase [31]. However, due to long exposure, the shrinkage of soil particles exceeds the optimal range of the reticular membrane structure. Therefore, its strength shows a weakening trend after reaching the maximum.

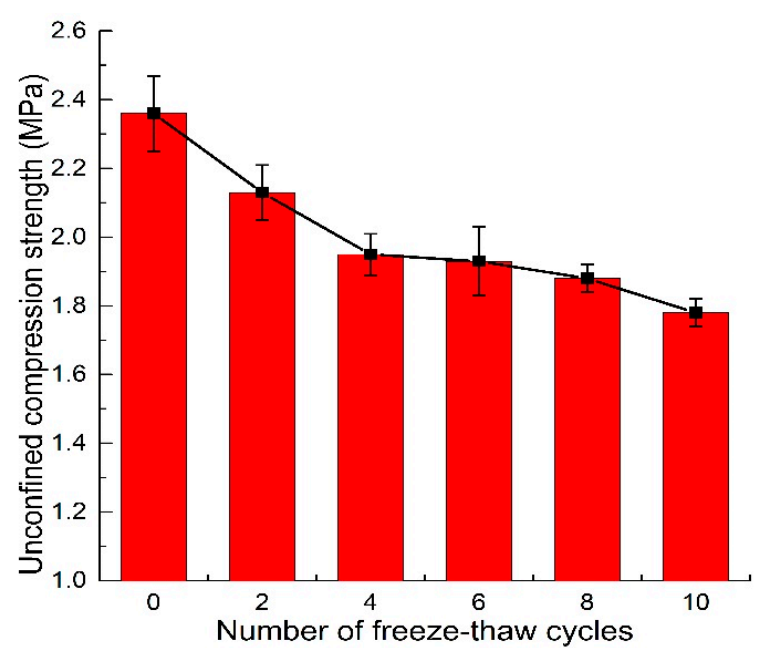

(a)

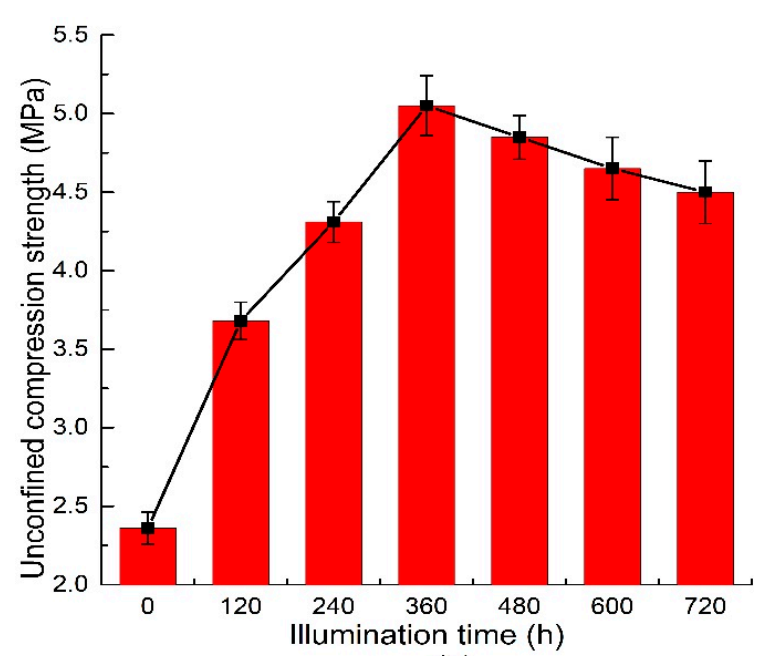

(b)

Figure 7. UCS vs. number of freeze-thaw cycles (a) and vs. illumination time (b) for soils tested.

\subsection{Seed Growth Test}

Table 5 shows the results of the seed growth test. In addition, Figure 8 illustrates the seed growth with different polymer concentrations after 30 days. It is observed that the vinyl acetate polymer has no adverse effect on plant vegetation. The vegetation grows and develops well after spraying with polymer. The germination in soil with $30 \%$ polymer is one day earlier, and the germination rate is also high. The structure and physical properties of the soil, such as water-retaining property and strength, were improved after the addition of polymer to the soil according to the water-retaining property test and the mechanical property test. This played a role in heat and moisture preservation for the germination and growth of vegetation. Therefore, vinyl acetate polymer has no adverse effect on vegetation growth, and will promote vegetation growth to a certain extent.

Table 5. The results of the seed growth test.

\begin{tabular}{|c|c|c|c|c|c|}
\hline \multirow{2}{*}{$\begin{array}{l}\text { Specimens } \\
\text { Reference }\end{array}$} & \multirow{2}{*}{$\begin{array}{c}\text { Polymer } \\
\text { Concentration }(\%)\end{array}$} & \multirow{2}{*}{$\begin{array}{l}\text { Germinating } \\
\text { Time (day) }\end{array}$} & \multicolumn{2}{|c|}{ Status of Vegetation Growth } & \multirow{2}{*}{$\begin{array}{l}\text { Development of } \\
\text { Surface Cracks }\end{array}$} \\
\hline & & & $\begin{array}{l}\text { Germination } \\
\text { Rate }^{1}\end{array}$ & $\begin{array}{c}\text { Growth } \\
\text { Situation }\end{array}$ & \\
\hline S29 & 0 & 6 & 0.6 & 0.7 & 0.7 \\
\hline S30 & 10 & 6 & 0.7 & 0.8 & 0.4 \\
\hline S31 & 20 & 6 & 0.8 & 0.9 & 0.1 \\
\hline S32 & 30 & 5 & 1 & 1 & 0 \\
\hline
\end{tabular}

${ }^{1}$ A big number means a high germination rate; ${ }^{2}$ A big number means a better growth situation; ${ }^{3}$ A big number means more cracks.

Vinyl acetate polymer was synthesized without the use of formaldehyde, halogen solvent or aromatic hydrocarbons, and also without mercury and other heavy metal elements and compounds. It will not adversely affect the survival of aquatic organisms and plant growth. The leachate of polymer reinforced soil in accordance with relevant Japanese standards, and the results show that the leachate is non-toxic. It is an ecological polymer. 


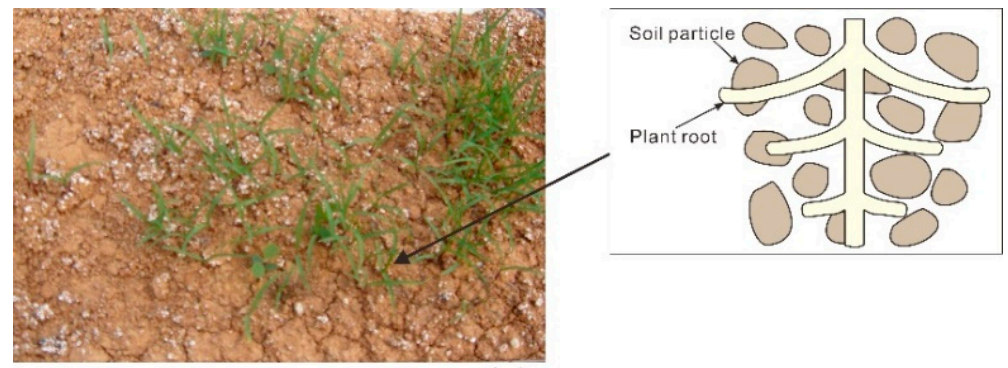

(a)

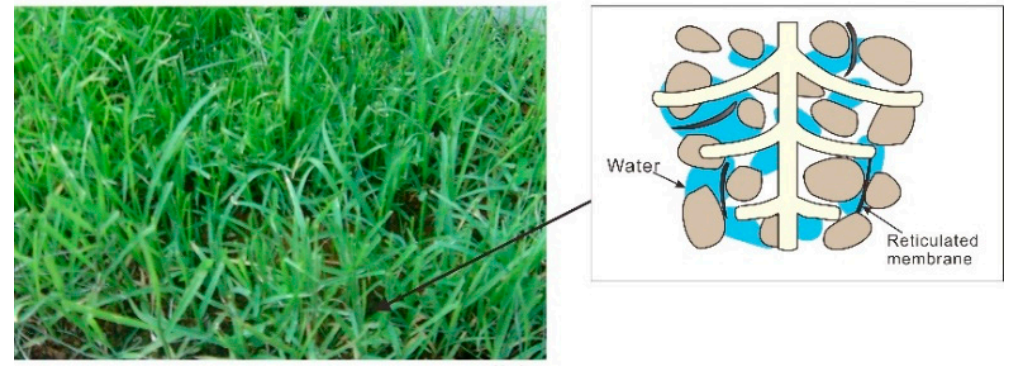

(b)

Figure 8. The picture and schematic diagram of seed growth with different polymer concentrations after 30 days: (a) $0 \%$; (b) $30 \%$.

\section{Field Test}

\subsection{Area Overview}

The site area is located in Ninghuai highway, Jiangsu, China (Figure 9). Also, the soil used in the laboratory experiments was obtained here. The soil slope on the site was the same chosen in the rainfall erosion test, i.e., $30^{\circ}$. The erosion of the slope surface was very serious. Although seeds had been sprayed on the surface of the soil after the construction of the slope, they were washed away before germinating, which seriously affected road safety and ecological vegetation greening.

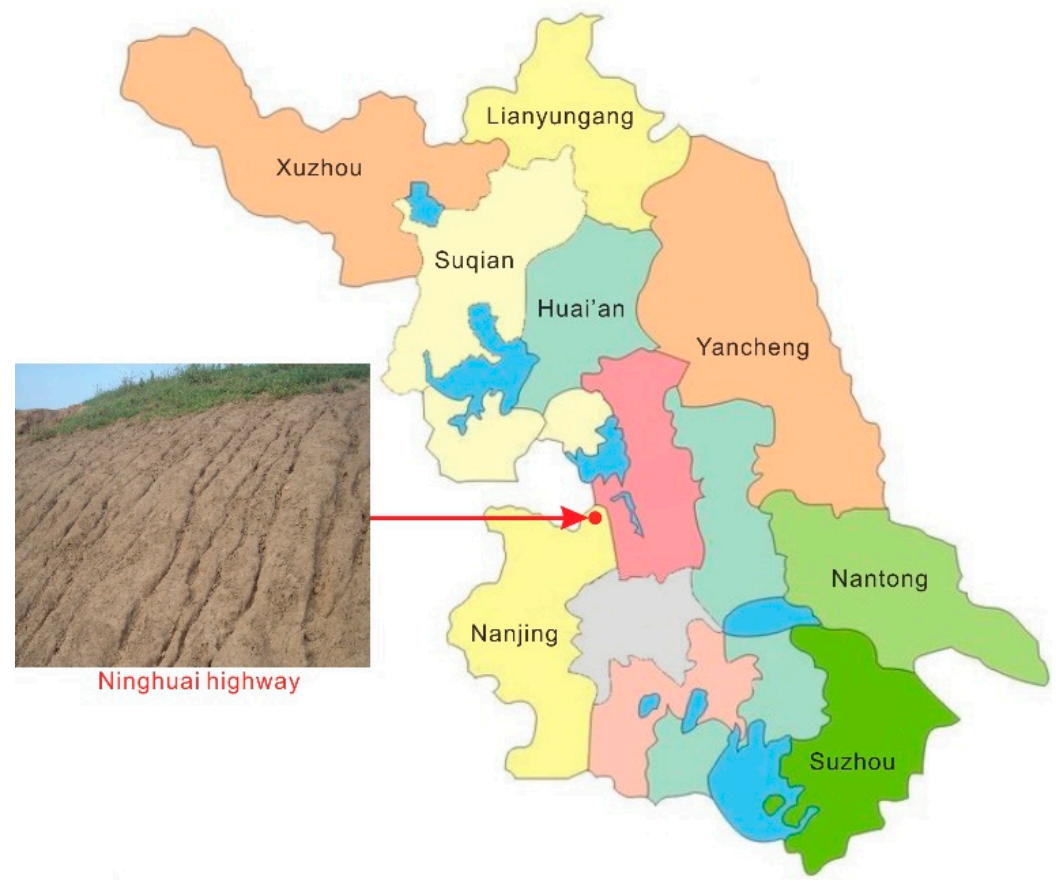

Figure 9. The location of the field tests in Jiangsu Province, China. 


\subsection{Field Test Scheme}

In this experiment, the application effect and economic cost were taken into account. The concentration of polymer was $20 \%$ and the spray volume was $3 \mathrm{~L} / \mathrm{m}^{2}$, which was determined by comprehensive consideration of indoor test results, field test conditions and economic costs. According to the relevant price standards in China, the price of the technology used on the slope was about $\$ 30 / \mathrm{m}^{2}\left(¥ 208 / \mathrm{m}^{2}\right)$. The specific experimental procedures are as follows:

(1) Level the slope surface: As the slope was excavated manually, the slope is not smooth. To carry out the subsequent experiments smoothly, the slope surface needs to be leveled.

(2) Sow the seeds: Organic fertilizers and other compound fertilizers are applied to make the vegetation grow in a better environment. Seeds for slope planting were also sown. Considering the characteristics of soil quality and climatic factors in the Nanjing area, three plant species, including bahiagrass, cynodon dactylon and trifolium repens, were selected for the field test, which all have the characteristics of root system development, heat resistance, cold resistance and drought resistance.

(3) Spray polymer: Dilute the vinyl acetate polymer to $20 \%$ concentration and spray it onto the surface of the slope with a spray amount of $3 \mathrm{~L} / \mathrm{m}^{2}$.

(4) Maintenance and evaluation: Because the germination of seeds requires specific temperature, water, sunlight and other aspects of the natural environment, the slope should be regularly sprayed with water conservation for the process of germination and growth of seeds. In addition, the vegetation growth and state of the slope were observed and recorded regularly. Also, the effect of vinyl acetate polymer was comprehensively evaluated.

\subsection{Field Test Effect Evaluation}

The results of comprehensive evaluation show that vinyl acetate polymer is effective for improving the erosion resistance of the topsoil on the slope by reducing the soil loss and protecting the vegetation growth. The state of the slope two months after the completion of spraying is shown in Figure 10a. As shown in Figure 10a, the surface structure of the slope, which was sprayed vinyl acetate polymer, was complete, without any obvious erosion marks. Moreover, the vegetation grew luxuriously, playing a good role in green slope protection. By comparison, the vegetation growth of the slope that was not sprayed with vinyl acetate polymer was very uneven, and the effect of ecological greening was poor. The surface gullies of the slope were very developed, and soil erosion was serious (Figure 10d).

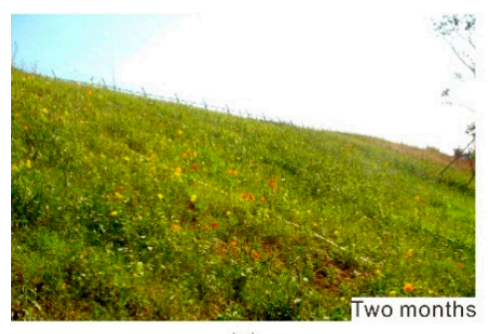

(a)

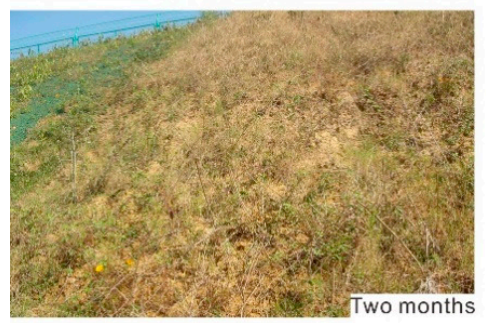

(d)

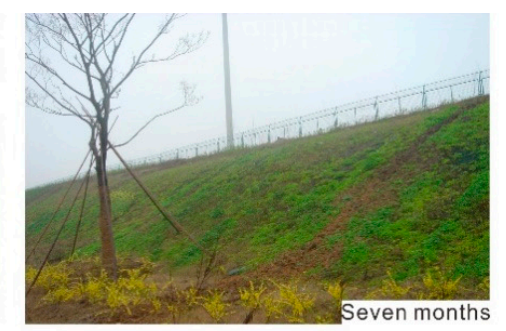

(b)

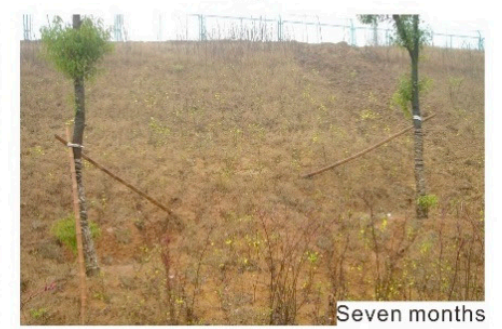

(e)

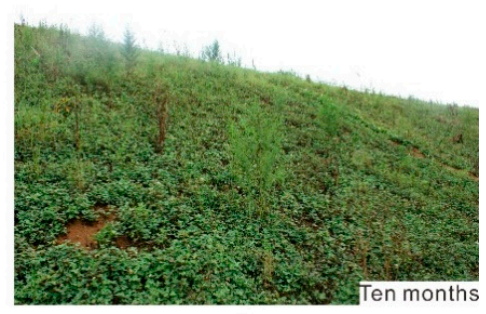

(c)

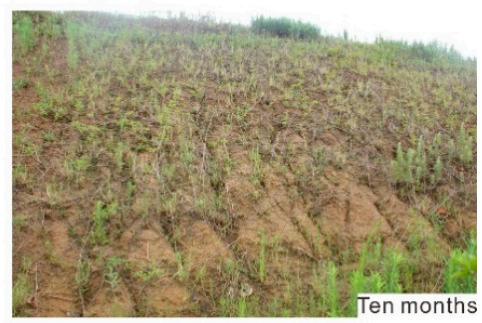

(f)

Figure 10. The state of the slope: $(\mathbf{a}-\mathbf{c})$ with polymer; $(\mathbf{d}-\mathbf{f})$ without polymer. 
The state of the slope seven months after the completion of spraying is shown in Figure 10b. As it was early spring, some of the plants had not yet sprouted. However, evergreen plants grew well, playing a better role in green slope protection. The vegetation did not have the effect of stabilizing the slope or greening at the slope that was not sprayed with vinyl acetate polymer. The surface gullies of the slope were highly developed, and soil erosion was serious (Figure 10e). The state of the slope ten months after the completion of spraying is shown in Figure 10c, and the state of the slope that was not sprayed with vinyl acetate polymer is shown in Figure 10f. As shown in Figure 10c,f, the states were the same as the states shown in Figure 10a,b,d,e. The surface structure of the slope with vinyl acetate polymer was complete, without any obvious erosion marks, and the surface gullies of the slope that was not sprayed with vinyl acetate polymer were highly developed, and soil erosion was serious. The vegetation grew well on the slope with vinyl acetate polymer compared with that without vinyl acetate polymer.

The surface soil of the untreated slope was washed away after precipitation. A part of the seeds was washed away with the runoff on the surface of the slope, causing soil erosion and a decrease in the amount of vegetation. After spraying polymer diluent on the surface of the slope, the strength, erosion resistance and durability of soil were improved. Seeds were not washed away by runoff. In addition, polymer was also able to improve the water-retaining property of soil, which can promote the growth of vegetation.

\section{Conclusions}

To test the water-related and mechanical properties of soil stabilization using a polymer soil stabilizer solution synthesized from vinyl acetate polymer, a water properties test, mechanical properties test, durability test and seed growth test were carried out in the laboratory. Also, the effect of the vinyl acetate polymer was verified by field tests. Based on the results obtained, the following conclusions can be drawn.

(1) In the water property test, the water-retaining property and the erosion resistance of soil can be improved effectively by spraying vinyl acetate polymer diluent onto soil surface under laboratory conditions. The evaporativity of the soil decreases gradually with the increase in stabilizer concentration. Soil can maintain a higher moisture content, which can promote the growth of vegetation. The erosion resistance of the soil can be improved effectively when the soil surface is sprayed with vinyl acetate polymer diluent. As the concentration of stabilizer increases, the erosion resistance of soil surface also increases.

(2) The mechanical properties test showed that the vinyl acetate polymer has a significant influence on the mechanical properties of soil under laboratory conditions. With the increase of polymer concentration, the unconfined compressive strength and cohesion of the soil increased greatly. The internal friction angle of the soil is relatively stable. However, the shear strength of the soil increases as the polymer concentration increases.

(3) In the durability test, the durability of the soil improves with the addition of vinyl acetate polymer under laboratory conditions. After $720 \mathrm{~h}$ of illumination or 10 freeze-thaw cycles, the soil still exhibits relatively high strength, which means it has a good durability in $720 \mathrm{~h}$ of illumination or 10 freeze-thaw cycles. The results of the seed growth test show that vinyl acetate polymer has no adverse effect on plant vegetation under laboratory conditions. The vegetation grows and develops well after spraying with the polymer.

(4) The results of the field test show that vinyl acetate polymer is effective for improving the erosion resistance of the topsoil on the slope by reducing the soil loss and protecting the vegetation growth. The slope surface treated with vinyl acetate polymer underwent much less erosion, and had well-grown vegetation.

Author Contributions: Data curation, J.L., Z.S., D.L. and Z.C.; Investigation, Z.S., Y.B. and Q.W.; Methodology, J.W. and J.L.; Writing-original draft, J.W., J.L. and Z.S.; Writing—review \& editing, D.P.K. and W.Q. 
Funding: This research was financially supported by the National Natural Science Foundation of China (grant number 41472241), the Fundamental Research Funds for the Central Universities (grant number 2016B05914) and Water Conservancy Science and Technology Project of Jiangsu Province, China (grant number 2017010).

Acknowledgments: We acknowledge the help of Ying Wang and Fan Bu of School of Earth Sciences and Engineering, Hohai University.

Conflicts of Interest: The authors declare no conflict of interest.

\section{References}

1. Lim, J.Y.; Chun, Y. The characteristics of asian dust events in northeast asia during the springtime from 1993 to 2004. Glob. Planet. Chang. 2006, 52, 231-247. [CrossRef]

2. McTainsh, G.H.; Lynch, A.W.; Tews, E.K. Climatic controls upon dust storm occurrence in eastern Australia. J. Arid Environ. 1998, 39, 457-466. [CrossRef]

3. Tang, C.S.; Wang, D.Y.; Shi, B.; Li, J. Effect of wetting-drying cycles on profile mechanical behavior of soils with different initial conditions. Catena 2016, 139, 105-116. [CrossRef]

4. Orts, W.J.; Sojka, R.E.; Glenn, G.M. Biopolymer additives to reduce erosion-induced soil losses during irrigation. Ind. Crop Prod. 2000, 11, 19-29. [CrossRef]

5. Saadeldin, R.; Siddiqua, S. Geotechnical characterization of a clay-cement mix. Bulletin of Engineering. Geol. Environ. 2013, 72, 601-608. [CrossRef]

6. Saeed, K.A.; Kassim, K.A.; Nur, H.; Yunus, N.Z.M. Strength of lime-cement stabilized tropical lateritic clay contaminated by heavy metals. KSCE J. Civ. Eng. 2015, 19, 887-892. [CrossRef]

7. Tang, H.; Li, X.; Li, M.; Song, L.; Wu, Z.; Xu, H. Properties and mechanism of cfbc fly ash-cement based stabilizers for lake sludge. J. Wuhan Univ. Technol.-Mater. Sci. Ed. 2012, 27, 750-753. [CrossRef]

8. Wang, Y.; Cui, Y.J.; Tang, A.M.; Tang, C.S.; Benahmed, N. Changes in thermal conductivity, suction and microstructure of a compacted lime-treated silty soil during curing. Eng. Geol. 2016, 202, 114-121. [CrossRef]

9. Xue, G.; Yilmaz, E.; Song, W.; Cao, S. Compressive Strength Characteristics of Cemented Tailings Backfill with Alkali-Activated Slag. Appl. Sci. 2018, 8, 1537. [CrossRef]

10. Chen, Z.G.; Tang, C.S.; Zhu, C.; Shi, B.; Liu, Y.M. Compression, swelling and rebound behavior of gmz bentonite/additive mixture under coupled hydro-mechanical condition. Eng. Geol. 2017, 221, 50-60. [CrossRef]

11. Latifi, N.; Marto, A.; Eisazadeh, A. Analysis of strength development in non-traditional liquid additive-stabilized laterite soil from macro- and micro-structural considerations. Environ. Earth Sci. 2015, 73, 1133-1141. [CrossRef]

12. Ma, C.; Qin, Z.; Zhuang, Y.; Chen, L.; Chen, B. Influence of sodium silicate and promoters on unconfined compressive strength of portland cement-stabilized clay. Soils Found. 2015, 55, 1222-1232. [CrossRef]

13. Escolano, F.; Sánchez, J.R.; Pacheco-Torres, R.; Cerro-Prada, E. Strategies on Reuse of Clayey Expansive Soils as Embankment Material in Urban Development Areas: A Case Study in New Urbanized Zones. Appl. Sci. 2018, 8, 764. [CrossRef]

14. Yang, Y.L.; Reddy, K.R.; Du, Y.J.; Fan, R.-D. Sodium hexametaphosphate (shmp)-amended calcium bentonite for slurry trench cutoff walls: Workability and microstructure characteristics. Can. Geotech. J. 2018, 55, 528-537. [CrossRef]

15. Shorin, V.A.; Kagan, G.L.; Vel'sovskii, A.Y. A new diagnostic instrument and method for stabilization of heaving soil in the beds of structures. Soil Mech. Found. Eng. 2008, 45, 144-147. [CrossRef]

16. Blanck, G.; Cuisinier, O.; Masrouri, F. Soil treatment with organic non-traditional additives for the improvement of earthworks. Acta Geotech. 2014, 9, 1111-1122. [CrossRef]

17. Eujine, G.N.; Chandrakaran, S.; Sankar, N. Accelerated subgrade stabilization using enzymatic lime technique. J. Mater. Civil Eng. 2017, 29. [CrossRef]

18. Khan, T.A.; Taha, M.R. Effect of three bioenzymes on compaction, consistency limits, and strength characteristics of a sedimentary residual soil. Adv. Mater. Sci. Eng. 2015. [CrossRef]

19. Onyejekwe, S.; Ghataora, G.S. Soil stabilization using proprietary liquid chemical stabilizers: Sulphonated oil and a polymer. Bull. Eng. Geol. Environ. 2015, 74, 651-665. [CrossRef]

20. Onyejekwe, S.; Ghataora, G.S. Stabilization of Quarry Fines Using a Polymeric Additive and Portland Cement. J. Mater. Civ. Eng. 2016, 28. [CrossRef] 
21. Rezaeimalek, S.; Nasouri, R.; Huang, J.; Bin-Shafique, S. Curing Method and Mix Design Evaluation of a Styrene-Acrylic Based Liquid Polymer for Sand and Clay Stabilization. J. Mater. Civ. Eng. 2018, 30. [CrossRef]

22. Gilazghi, S.T.; Huang, J.; Rezaeimalek, S.; Bin-Shafique, S. Stabilizing sulfate-rich high plasticity clay with moisture activated polymerization. Eng. Geol. 2016, 211, 171-178. [CrossRef]

23. Rivera-Gomez, C.; Galan-Marin, C.; Bradley, F. Analysis of the Influence of the Fiber Type in Polymer Matrix/Fiber Bond Using Natural Organic Polymer Stabilizer. Polymers 2014, 6, 977-994. [CrossRef]

24. Naeini, S.A.; Naderinia, B.; Izadi, E. Unconfined compressive strength of clayey soils stabilized with waterborne polymer. KSCE J. Civ. Eng. 2012, 16, 943-949. [CrossRef]

25. Zezin, A.B.; Mikheikin, S.V.; Rogacheva, V.B.; Zansokhova, M.F.; Sybachin, A.V.; Yaroslavov, A.A. Polymeric stabilizers for protection of soil and ground against wind and water erosion. Adv. Colloid Interface Sci. 2015, 226, 17-23. [CrossRef] [PubMed]

26. Collins, R.; Zhang, M.; Zhang, X.; Hulsey, L.; Ravens, T.; Van Veldhuizen, R. Evaluation of geofibers and nontraditional liquid additives on erodible slopes in interior alaska. Geotext. Geomembr. 2015, 43, 412-423. [CrossRef]

27. Liu, J.; Bai, Y.; Song, Z.; Lu, Y.; Qian, W.; Kanungo, D.P. Evaluation of strength properties of sand modified with organic polymers. Polymers 2018, 10, 287. [CrossRef]

28. Liu, J.; Song, Z.; Lu, Y.; Wang, Q.; Kong, F.; Bu, F.; Kanungo, D.P.; Sun, S. Improvement effect of water-based organic polymer on the strength properties of fiber glass reinforced sand. Polymers 2018, 10, 836. [CrossRef]

29. An, N.; Tang, C.S.; Xu, S.K.; Gong, X.P.; Shi, B.; Inyang, H.I. Effects of soil characteristics on moisture evaporation. Eng. Geol. 2018, 239, 126-135. [CrossRef]

30. Tang, C.S.; Shi, B.; Liu, C.; Suo, W.B.; Gao, L. Experimental characterization of shrinkage and desiccation cracking in thin clay layer. Appl. Clay Sci. 2011, 52, 69-77. [CrossRef]

31. Wang, D.Y.; Tang, C.S.; Shi, B.; Li, J. Studying the effect of drying on soil hydro-mechanical properties using micro-penetration method. Environ. Earth Sci. 2016, 75, 1009. [CrossRef]

(C) 2019 by the authors. Licensee MDPI, Basel, Switzerland. This article is an open access article distributed under the terms and conditions of the Creative Commons Attribution (CC BY) license (http:/ / creativecommons.org/licenses/by/4.0/). 